DOI:

Cite this as:

Atin, Supri, Yusuf, Munawir. Evaluation Of Equality Education Program In PKMB Nurul Mubtadiin As A

Nonformal Inclusion Institution. Indonesian Journal of Disability Studies (IJDS).2018: Vol. 5(2): PP 180 - 184.

\title{
EVALUATION OF EQUALITY EDUCATION PROGRAM IN PKMB NURUL MUBTADIIN AS A NONFORMAL INCLUSION INSTITUTION
}

\author{
${ }^{1 *}$ Supri Atin, ${ }^{2}$ Munawir Yusuf \\ ${ }^{1,2}$ Magister Pendidikan Luar Biasa, Pascasarjana Universitas Sebelas Maret, Surakarta, Indonesia
}

\begin{abstract}
This study aims to describe the evaluation of the Package B PKBM Nurul Mubtadiin equality education program as a non-formal inclusion institution which covers the context of the evaluation of the Package B equality education program at PKBM Nurul Mubtadiin, evaluation of the input of Package B PKBM Nurul Mubtadiin's equality education program and evaluation of process implementation and the quality of the results of the Package B equality education program at PKBM Nurul Mubtadiin. This study uses a descriptive qualitative approach using the method of observation, interviews. One respondent was 1 blind student, 1 Tutor and PKBM Chairperson Nurul Mubtadin.
\end{abstract}

Keywords: program evaluation, inclusion institutions, PKBM

\section{Latar Belakang}

Pembangunan pendidikan dasar yang dilakukan dengan berbagai upaya telah mencapai tahap yang cukup berarti, namun masih jauh dari harapan. Hal itu terlihat dalam pemerataan dan peningkatan akses pendidikan dasar serta penigkatan mutu, relevasi dan daya saing di tingkat SD/MI, dan SMP/MTs. Faktor penyebab belum tuntasnya pendidikan dasar 9 tahun merut Ace Suryadi (2006) karena: tinggal di daerah terpencil dan terisolasi sehingga tidak dapat menjangkau sekolah, tidak bersekolah, karena alasan ekonomi, bekerja mencari nafkah untuk membantu orang tua, tinggal dimasyarakat yang secara budaya belum menganggap pendidikan sebagai sesuatu yang penting atau tinggal di daerah bencana atau konflik. Oleh karena itu, untuk mendukung penuntasan wajib belajar pendidikan 9 tahun bagi daerah dan masyarakat miskin, terpencil dan terisolasi diperlukan upaya khusus melalui penerapan pelaksanaan pendidikan non formal kesetaraan paket A, B, C yang berfungsi sebagai pengganti, penambah atau pelengkap. Menurut Sisdiknas (2003:4), pendidikan

* Corresponding author: Supri Atin

atinplb@student.uns.ac.id

Published online at http://IJDS.ub.ac.id/

Copyright $\odot 2018$ PSLD UB Publishing. All Rights Reserved nonformal adalah jalur pendidikan di luar pendidikan formal yang dapat dilaksanakan secaraterstruktur dan berjenjang.

Pusat kegiatan belajar masyarakat pada dasarnya merupakan tempat dimana orangorang atau masyarakat dapat mengikuti program kegiatan belajar. PKBM mendorong masyarakat agar belajar secara mandiri melalui penguatan, pemberdayaan pendidikan. PKBM Nurul Mubtadiin memiliki posisi yang baik sebagai salah satu PKBM dalam menyelenggarakan program peningkatan sumberdaya manusia melalui pendidikan non formal. Hal tersebut diajuakan pada undang undang No 20 Tahun 2003 tentang pendidikan nasional yang menetapkan PKBM sebagai salah satu satuan pendidikan non formal. Menurut Fasli Jalal menyatakan bahwa PKBM adalah suatu wadah bagi setiap warga masyarakat agar mereka lebih berdaya.

Pendidikan kesetaraan secara umum bertujuan untuk memberikan kesempatan belajar pendidikan dasar dan menengah yang bermutu dan relevan dengan kebutuhan warga belajar (peserta didik) yang tidak memiliki kesempatan belajar pada pendidikan formal dengan penekanan pada penguasaan pengetahuan dan keterampilan fungsional serta pengembangan sikap dan kepribadian 
professional dalam rangka mendukung pendidikan sepanjang hayat.

Warga belajar yang dimaksudkan pada pendidikan non formal adalah berasal dari masyarakat yang kurang beruntung, tidak pernah sekolah, putus sekolah dan putus lanjut serta usia produktif yang belum memiliki pengetahuan dan kecakapan hidup serta warga masyarakat lain yang perlu layanan khusus dalam memenuhi kebutuhan hidupnya sebagai dampak dari perubahan peningkatan taraf hidup, ilmu dan teknologi.

Dari latar belakang diatas, peneliti tertarik untuk melakukan penelitian tentang bagaimana evaluasi program pendidikan kesetaraan paket B PKBM Nurul Mubtadiin Kawunganten sebagai lembaga inklusi nonformal

\section{Metode Penelitian}

Menurut Syaiful Bahri Djamarah dan Aswan Zain (2010: 41-52), "Metode adalah suatu cara yang dipergunakan untuk mencapai tujuan yang telah ditetapkan" Penelitian ini menggunakan metode kualitatif deskriptif, data diperoleh dengan menggunakan angket, wawancara dan observasi. Observasi dapat menghemat biaya seperti yang di katakana Nurul Zuriah (2007:173), "metode observasi sebagai alat pengumpul data, dapat dikatakan berfungsi ganda,sederhana dan dapat dilakukan tanpa menghabiskan banyak biaya" Responden dalam penelitian ini adalah 1 peserta didik tunanetra, 1 Tutor dan pengelola PKBM.

\section{Hasil dan Pembahasan \\ 3.1. Evaluasi Konteks Program Pendidikan Kesetaraan Paket B}

Istilah program Suharsimi Arikunto dan Cepi Safruddin (2010:3), membagi pengertian menjadi dua yaitu pengertian secara khusus dan umum. Menurut pengertian secara umum program dapat diartikan sebagai "rencana". Apabila "program" ini langsung dikaitkan dengan evaluasi program maka program didefinisikan sebagai suatu unit atau kesatuan kegiatan yang merupakan realisasi atau implementasi dari suatu kebijakan, berlangsung dalam proses berkesinambung, dan terjadi dalam suatu organisasi yang melibatkan sekelompok orang. Sedangkan Djuju Sujana (2000:267), mendenifisikan evaluasi sebagai kegiatan sistematis untuk mengumpulkan, mengolah, dan menyajikan data atau informasi yang diperlukan sebagai masukan untuk pengambilan keputusan. Definisi lain dikemukakan oleh Wirawan (2011:7), yang menguraikan bahwa evaluasi adalah proses mengumpulkan dan menyajikan informasi mengenai obyek evaluasi, menilainya dengan standar evaluasi dan evaluasinya dipergunakan untuk mengambil keputusan mengenai obyek evaluasi.

Program pendidikan kesetaraan Paket B Nurul Mubtadiin bertujuan untuk memberikan kesempatan kepada masyarakat untuk dapat menikmati pendidikan karena beragam keterbatasan serta untuk meningkatkan pengetahuan, ketrampilan dan sikap peserta didik. PKBM Nurul Mubtadiin berfungsi sebagai tempat berlangsungnya proses kegiatan belajar yang bersifat nonformal untuk memudahkan masyarakat memperoleh pengetahuan dan keterampilan, sumber informasi dan sebagai wadah belajar masyarakat. Hadirnya PKBM Nurul Mubtadiin diketahui dari analisis kebutuhan dimasyarakat dan minat pendidikan yang selalu meningkat dan adanya program pemerintah wajib belajar 9 tahun. Sebagai tolak ukur keberhasilan program adalah peserta didiknya lulus semua dengan memperoleh ijasah paket B yang dapat digunakan untuk melanjutkan kejenjang yang lebih tinggi.

\section{Evaluasi Input Program Pendidikan Kesetaraan Paket B}

PKBM Nurul Mubtadiin melaksanakan perkruitmen calon peserta didik, tutor dan menyediakan sarana dan prasaranan belajar, melaksanakan pembelajaran dan menjamin kelangsungan pelaksanaan proses belajar mengajar sesuai program yang ditetapkan. PKBM Nurul Mubtadiin memiliki 8 tutor 
untuk program Paket B. Tenaga Pendidik adalah warga masyarakat yang memiliki kelebihan baik dibidang pengetahuan, keterampilan dan sikap yang mampu serta mau mengalihkan apa yang dimilikinya pada peserta didik melalui proses pembelajaran, orang yang bertanggungjawab terhadap pelaksanaan pendidikan dengan sasaran peserta didik. Umar Tirtaraharja dan La Sulo dalam Dwi Siswoyo dkk, (2007:126). Tutor berlatar belakang Sarjana semua dan mengampu tiga kelas sekaligus. Untuk menjadi tutor mereka harus melamar sesuai dengan kualifikasi yang telah ditentukan oleh pihak PKBM Nurul Mubtadiin dan ketika ada lowongan. Adapun daftar tutor program Paket B adalah sebagai berikut:

Tabel 1 Daftar Tutor Program paket B

\begin{tabular}{|c|l|l|l|l|}
\hline No & Nama Tutor & TTL & Agama & $\begin{array}{l}\text { jjazah } \\
\text { Terakhir }\end{array}$ \\
\hline 1. & $\begin{array}{l}\text { Budi } \\
\text { Suseno }\end{array}$ & $\begin{array}{l}\text { Cilacap, 12 } \\
\text { Agustus 1984 }\end{array}$ & Islam & S1 \\
\hline 2. & Saino & $\begin{array}{l}\text { Cilacap, 5 } \\
\text { Maret 1968 }\end{array}$ & Islam & S1 \\
\hline 3. & $\begin{array}{l}\text { Rahmat } \\
\text { Salim }\end{array}$ & $\begin{array}{l}\text { Cilacap, 16 } \\
\text { Juni 1979 }\end{array}$ & Islam & S1 \\
\hline 4. & $\begin{array}{l}\text { Tri } \\
\text { Wahyuni }\end{array}$ & $\begin{array}{l}\text { Cilacap, 9 Mei } \\
\text { 1982 }\end{array}$ & Islam & S1 \\
\hline 5. & Wahyu & $\begin{array}{l}\text { Cilacap, 21 } \\
\text { Maret 1982 }\end{array}$ & Islam & S1 \\
\hline 6. & Supri Atin & $\begin{array}{l}\text { Cilacap, 7 } \\
\text { April 1985 }\end{array}$ & Islam & S1 \\
\hline 7. & $\begin{array}{l}\text { Titi } \\
\text { Matuni'mah }\end{array}$ & $\begin{array}{l}\text { Ciamis, 14 } \\
\text { Oktober 1992 }\end{array}$ & Islam & S1 \\
\hline 8. & Trubus & $\begin{array}{l}\text { Cilacap, 27 } \\
\text { Januari 1990 }\end{array}$ & Islam & S1 \\
\hline
\end{tabular}

Sedangkan peserta didik kesetaraan Paket B adalah warga masyarakta khususnya wilayah kecamatan Kawunganten. Sistem perkruitan peserta didik dilakukan dengan cara mensosialisasikan program kesetaraan Paket B melalui tokoh masyarakat kecamatan Kawunganten. Dalam perekrutan tidak ada kualifikasi khusus dan tidak membedakan antara anak berkebutuhan khusus dengan anak normal pada umumnya. Bagi warga masyarakat yang ingin mendaftar bisa langsung ke PKBM Nurul Mubtadiin untuk melakukan kontrak belajar seperti waktu, tempat dan administrasi. Waktu belajar dilaksanakan tiga kali dalam seminggu dan bertempat di MA Nurul Huda.

\subsection{Evaluasi Proses dan Hasil Pembelajaran \\ 3.2.1. Materi dan Kurikulum}

Ada 6 bidang studi (Pendidikan Kwarganegaraan, Matematika, Bahasa Indonesia, Ilmu Pengetahuan Alam, Bahasa Inggris, dan Ilmu Pengetahuan Sosial) yang diberikan kepada peserta didik. Materi yanag diberikan tutor disusun dan ditulis dalam modul untuk membantu peserta didik dalam memahami materi. Kurikulum yang digunakan adalah Kurikulum Tingkat Satuan Pendidikan (KTSP) dari Dinas Pendidikan. Tidak ada perbedaan materi dan kurikulum antara peserta didik berkebutuhan khusus dengan yang lain.

\subsubsection{Model}

Model pembelajaran yang digunakan dalam pelaksanaan kegiatan Paket B di PKBM Nurul Mubtadiin dengan Cara Belajar Siswa Aktif (CBSA). Penggunaan ini dimaksudkan agar peserta didik Paket B dapat belajar secara aktif dan mandiri sehingga dalam pelaksanaannya peserta didik diberikan materi yang disusun dalam modul yang kemudian diberikan penjelasan. Bagi peserta didik berkebutuhan khusus dapat mengikuti model pembelajaran tersebut. Namun model ini memiliki kelemahan yakni peserta didik yang normal, umumnya malu bertanya. Untuk mengaktifkan kelas, tutor menggunakan media sebagai alat yang dapat merangsang pikiran, perasaan, perhatian dan minat peserta didik. Media Pembelajaran Paket B yang digunakan tutor berupa whiteboard, buku modul, gambar untuk pembelajaran praktik.

\subsubsection{Evaluasi Pembelajaran}


Evaluasi pembelajaran merupakan salah satu komponen untuk menentukan keberhasilan program kesetaraan Paket B. Farida Yusuf Tayibnapis (2000:14), evaluasi produk untukmembantu membuat keputusan selanjutnya, baik mengenai hasil yang telah dicapai maupun apa yang dilakukan setelah program itu berjalan. Evaluasi pembelajaran memiliki fungsi di dalam kelas sebagai penentu hasil urutan pengajaran yang langung bertalian dengan penguasaan tujuan - tujuan yang akan dicapai dalam satu kegiatan pembelajaran dan juga menilai unsur - unsur yang relevan pada urutan perencanaan, pelaksanaan pembelajaran dan rancangan kurikulum serta rancangan pengajaran. Evaluasi untuk mengamati hasil belajar peserta didik dengan tujuan untuk memperbaiki pengajaran dan penguasaa tujuan tertentu dalam kelas. Proses pelaksanaan evaluasi pembelajaran yang dilakukan oleh tutor Paket B di PKBM Nurul Mubtadiin adalah evaluasi proses, evaluasi harian dan evaluasi semester. Evaluasi proses dilaksanakan pada saat pemberian materi dengan memberikan pertanyaan secara lisan. Evaluasi harian diberikan kepada peserta didik untuk mengetahui daya serap setelah mempelajari materi pada satu pokok bahasan. Sedangankan evaluasi semester dilakukan untuk mengetahui tingkat keberhasilan peserta didik setelah belajar selama satu semester.

\section{Kesimpulan}

Berdasarkan evaluasi konteks, program kesetaraaan Paket B, dapat dikatakan sudah baik ditunjukan dengan fungsi lembaga yang jelas, penyelenggaraan program pendidikan kesetaraan didasarkan pada kebutuhan masyarakat dan adanya tujuan program serta indicator ketercapaian program yang jelas dan baik.

Proses pembelajaran berjalan lancar dan memiliki acuan standar penilaian yang baik. dibuktikan dengan adanya peningkatan kualitas yang sudah didapatkan oleh peserta didik dan persentasi kelulusan peserta didik adalah $100 \%$ sesuai indicator ketercapaian program kesetaraan Paket di PKBM Nurul Mubtadiin.
Perlu adanya penambahan Tutor sebagai GPK (Guru Pendamping Khusus) bagi peserta didik berkebutuhan khusus sehingga memudakan anak dalam menerima pembelajaran. Sarana dan prasarananya juga perlu memperhatikan anak berkebutuhan khusus sehingga mereka merasa terlayani dengan baik tidak dibedakan dengan yang lain.

\section{Daftar Pustaka}

Departemen pendidikan nasional. (2008). Pengembangan model - model kurikulum pendidikan layanan khusus pendidikan non formal program paket A untuk daerah bencana alam. Diperoleh dari file.upi.edu/Direktori/SPS/PRODI.../PKBM_da $n \_m o d e l \_P e n g e m b a n g a n n y a . p d f$

Djudju Sudjana. (2000). Manajemen Program Pendidikan untuk Pendidikan Luar Sekolah dan Pengembangan Sumber Daya Manusia. Bandung: $\quad$ Falah Production

Farida Yusuf Tayibnapis. (2000). Evaluasi Program. Jakarta: PT. Rineka Cipta

Nandi, W. (2006). Anak yang membutuhkan pendidikan khusus. diperoleh dari file.upi.edu/Direktori/SPS/PRODI.../PKBM_da n_model_Pengembangannya.pdf

Nofita, N.A. (2013). Hambatan - hambatan warga belajar dalam proses pembelajaran program paket $\mathrm{C}$ di kecamatan pancung soal kabupaten pesisir selatan. Jurnal. Spectrum PLS. Vol 1.No 1

Nurul Zuriah. (2007). Metodologi Penelitian Sosial dan Pendidikan. Jakarta: PT. Bumi Aksara.

Suharsimi Arikunto dan Cepi Safrudin. (2009). Evaluasi Program Pendidikan: Pedoman Teoritis Praktis Bagi Mahasiswa dan Praktisi Pendidikan, cetakan ketiga. Jakarta: Bumi Aksara.

Septiani, M. (2015). Pengalaman pusat kegiatan belajar masyarakat (PKBM) dalam memfasilitasi masyarakat belajar sepanjang hayat. Jurnal. Jurnal ilmiah Visi PPTK PAUDNI. Vol 10 No 2 diperoleh dari journal.unj.ac.id/unj/index.php/jiv/article/down load/3744/2788 
DOI:

Surandi, H.W. (2016). Peranan pusat kegiatan belajar masyarakat (PKBM) dalam membentuk karakter siswa PKBM di kelurahan patangpuluhan Yogyakarta. Skripsi. Yogyakarta: FKIP diperoleh dari https://pendidikannonformalsimal.files.wordpre ss.com/.../juknis-standar- pkbm-2013.pdf
Wirawan. (2011). Evaluasi Teori, Model, Standar, Aplikasi, Dan Profesi. Jakarta : Rajawali Pers.

Undang - undang Nomor 20 Tahun 2003Undang - undang Nomor 32 ayat $(1,2)$ Panduan Penyelanggaraan Pusat Belajar masyarakat, Balai Pengembangan Pendidikan Luar Sekolah dan Pemuda (BP-PLSP), Jayagiri, 2003, hlm. 20. 